\title{
Problemas en torno a la caracterización del viviente como sistema
}

\author{
Problems concerning the characterization \\ of the living being as a system
}

\author{
FRANCISCO GÜELL PELAYO \\ Universidad de Navarra, ICS, Mente y cerebro: biología y subjetividad en la filoso- \\ fía y en la neurociencia contemporáneas (España)
}

Recibido: 17-1-2013

Aprobado definitivamente: 26-2-2013

\section{RESUMEN}

Traigo a colación observaciones sobre problemas que subyacen a muchas de las reflexiones de filosofía de la biología entorno a la caracterización del viviente y la noción de función biológica. Alerto sobre la suplantación de la realidad por información científica inexacta, nocionesentificadas y modelos teóricos preconcebidos. Abogo por el análisis, antes de cualquier otra reflexión, de la relación entre la unidad y la multiplicidad de notas del viviente, análisis que explica la distintiva individualidad del organismo. Finalmente, anuncio el paradigma constitucional como una nueva aproximación al viviente, marco que toma como punto de partida al viviente como realidad estructurante.

\author{
PALABRAS CLAVE \\ SISTEMA VIVO, UNIDAD, FUNCIÓN, INDIVIDUALIDAD, ZUBIRI
}

\footnotetext{
ABSTRACT

This paper aims to deal with some problems underlying contemporary reflections on philosophy of biology, particularly the definition of living being and the idea of biological function. I warn about the danger of taking for granted imprecise scientific information and biased theoretical models. I defend the analysis of the relationship between unity and multiplicity as key features 
of the living being, which highlights the distinctive individuality of the organism. Finally, I introduce the constitutional paradigm as a new approach to the study of the living being, a frame which takes, as its starting point, the living being as «structuring reality».

KEY WORDS

LIFE SYSTEM, UNITY, FUNCTION, INDIVIDUALITY, ZUBIRI

LA FILOSOFÍA DE LA BIOLOGÍA ES PRESENTADA como una disciplina que se ramificó desde la filosofía de la ciencia, y sin ser fácil de definir por su amplio espectro de intereses, ${ }^{1}$ suele explicarse mediante la clasificación de los distintos tópicos que aborda. Una de las cuestiones centrales que ha tematizado esta disciplina discurre sobre la caracterización del viviente. En la actualidad, encontramos varias teorías y aproximaciones que, fundamentalmente, proponen modelos que intentan mostrar la peculiaridad de los sistemas vivos.

En este artículo pretendo realizar algunas observaciones sobre problemas que, en mi opinión, subyacen a muchas de las reflexiones y de las encendidas discusiones en torno a la caracterización del viviente y a la función biológica. Trataré de mostrar la necesidad de traer a un primer plano algunos aspectos epistemológicos y ontológicos que, pienso, han alejado de la realidad del viviente a muchas de las reflexiones filosóficas.

\section{SOBRE EL DATO CIENTÍFICO Y EL HECHO BIOLÓGICO}

Parece obvio que para llevar a cabo una reflexión filosófica sobre la biología, y más concretamente sobre la caracterización del viviente, hemos de conocer «la biología». Para tener conocimiento del viviente contamos, por un lado, con lo que se puede denominar conocimiento ordinario: sabemos qué es un perro, un gato, y todo un elenco de centenares de animales que, sin haberlos visto jamás, «sabemos» que son vivientes. Fuera del ámbito de lo académico-científico, nadie duda de lo que es y no es un viviente. El conocimiento ordinario nos sitúa intuitiva pero confiadamente en la realidad; pero este conocimiento parece que no es suficiente. Necesitamos de uno más hondo si lo que nos proponemos es describir lo característico de lo que está vivo y definir al viviente frente a otras realidades.

Para conocer lo que llamaré la «cruda realidad» del viviente hemos de recurrir, además, a lo que nos ofrecen las «ciencias biológicas»: la composición, el dinamismo intracelular, la organización celular, el comportamiento, la reproducción, la relación del viviente con el medio..., parece que tener presente estas y otras consideraciones nos ofrece un conocimiento amplio de lo que es un (2008)

1 P. E. Griffiths, «Biology, Philosophy of», Stanford Encyclopedia of Philosophy, 
viviente. Las ciencias biológicas, con lo dicho, nos proporcionan unas descripciones y datos científicos imprescindibles donde se nos presenta la realidad a la que aproximarnos filosóficamente. Por este motivo entiendo que un ejercicio de la filosofía de la biología «fiel» a la realidad de que pretende dar cuenta ha de ir ligado a un interés y constante compromiso con la «biología».

Pero el dato científico, y esto es importante tenerlo presente, no es el hecho biológico. Cuando nos proponemos describir o definir a un viviente frente a otros sistemas, el «viviente» no es el dato ni las descripciones: la información científica pretende mostrar el «hecho biológico». Si digo esto es porque, normalmente, el quehacer filosófico comprometido con el dato científico suele tomar a este acríticamente, como si lo científico fuera el mismo hecho biológico. Esta confianza en el dato científico es compartida por los mismos científicos: no parece razonable dudar de las descripciones de un manual científico de referencia o de la información científica publicada en revistas de alto impacto.

Pues bien, he de alertar que la comunidad científica no posee ningún cuidado con el lenguaje en las descripciones del hecho biológico. Para los objetivos estrictamente científicos, esta falta de precisión puede no ser relevante, pero para reflexiones de carácter interdisciplinar, entender la realidad de forma incorrecta tiene, necesariamente, fatales consecuencias: el punto de partida de la reflexión no es la «cruda realidad». Un llamativo ejemplo a este respecto es la descripción que encontramos sobre la primera mitosis tras la fecundación. Tal y como he mostrado en otro lugar, ${ }^{2}$ en los principales manuales de embriología se afirma que, tras la fecundación, los pronúcleos masculino y femenino se atraen, se fusionan, y el material genético se mezcla. ${ }^{3}$ Pues bien, esta descripción es del todo imprecisa. Afirmar que el material genético procedente del padre y de la madre se «mezcla», se «entremezcla» o se «recombina» tras la fusión de los pronúcleos, puede dar a entender que, con esa mezcla, aparece un nuevo ADN, o que se constituye un ADN distinto del que había antes de la fusión de los pronúcleos. Esto aquí dicho es, sencillamente, una falacia. En la primera mitosis

$2 c f$. F. Güell, El estatuto biológico y ontológico del embrión humano: el paradigma epigenético del siglo XXI desde la teoría de la esencia de Xavier Zubiri, Berna: Peter Lang, 2013, (en prensa).

3 En bibliografía de referencia encontramos el uso de términos como «entremezclamiento de los cromosomas maternos y paternos» (B. M. Carlson, Embriología humana y biología del desarrollo, $4^{\circ}$ ed., Barcelona: Elsevier España S.L., 2009, p. 31); «El cigoto contiene una nueva combinación de cromosomas» (K. L. Moore, T. V. N. Persaud, Embriología clínica, $8^{\circ}$ ed., Barcelona: Elsevier España S.L, 2008, p. 33); «el cigoto posee una nueva combinación de cromosomas» (T. W. Sadler, Langman's medical embryology, $11^{\circ}$ ed., Maryland: Lippincott Williams \& Wilkins, 2010, p. 38); «los cromosomas paternos y maternos se constituyen, y se mezclan» (N. López Moratalla y M. Iraburu, Los quince primeros días de una vida humana, $2^{\circ}$ ed., Pamplona: Eunsa, 2006, p. 78). 
tras la interacción de los gametos -y al igual que en las siguientes mitosis- los cromosomas de origen paterno y materno se alinean en el ecuador de la célula y, por decirlo así, «sin tocarse», se distribuyen de modo ordenado en el citoplasma. En la fecundación no se da la mezcla o recombinación que sí observamos y podría afirmarse en la profase de la meiosis I que acontece en la formación de los gametos (el denominado crossing over). He podido comprobar a lo largo de varios años que, como consecuencia de estas descripciones científicas, muchos académicos y gran parte de la sociedad piensa que en la doble hélice de la molécula de ADN de un individuo, una de las hebras proviene de la madre y otra del padre, y que esta «combinación» ocurre en la fecundación. No voy a entrar aquí en detalles, pero ocurre el mismo problema cuando se afirma que los pronúcleos se fusionan; pues bien, no existe tal fusión: las membranas de los pronúcleos se acercan, y sin tocarse, se desintegran. Es probable que los manuales tomen prestadas explicaciones de tratados anteriores; en el caso de la fusión de los pronúcleos, por ejemplo, nos podemos remontar a los manuales de biología del desarrollo de principios del $\mathrm{XX},{ }^{4}$ cuando la imprecisión respondía a las limitaciones de los medios que disponían para observar la «cruda realidad».

Además de la falta de precisión en las descripciones, la comunidad científica, en su ejercicio, considera, sin percatarse, nociones científicas abstractas como hechos biológicos. Esta entificación se aprecia, por ejemplo, en el modo con que se alude a algunas estructuras celulares de vital importancia. Difícil de creer es lo acontecido con el «genoma». En otro lugar ${ }^{5}$ he mostrado cómo esta noción teórica, que alude al concreto orden de nucleótidos repetidos que encontramos en las moléculas de ADN de las células de un individuo, se ha tomado como una realidad física. En la realidad física no encontramos «un genoma». El genoma es una abstracción. Lo que encontramos, como decía, es una multiplicidad de moléculas de ADN que, en condiciones normales, posee el mismo orden de nucleótidos en las células de un mismo individuo. Considero urgente llamar la atención de esta y otras entificaciones que, de forma alarmante, se produce en las ciencias de la vida, ciencias que, en principio, se caracterizan por estar apegadas a la realidad.

Además de las descripciones imprecisas y la entificación de ciertas nociones, existe un tercer tipo de error sobre el que he de llamar la atención. Me serviré de un ejemplo ilustrativo. En la bibliografía especializada se afirma que el genoma del embrión no comienza su expresión hasta completar, tras la fecundación, las primeras divisiones mitóticas. ${ }^{6}$ Una lectura atenta de la me-

$4 \quad c f$. W. P. Manton, Syllabus of Lectures on Human Embryology, $3^{\circ}$ ed., Philadelphia: F. A. Davis Company, Publishers, 1906, p. 37.

5 F. Güell, op. cit.

6 Por ejemplo, $c f$. C. Wong, et al. «Non-invasive imaging of human embryos before 
todología nos muestra que se seleccionan genes concretos cuya expresión se considera representativa del desarrollo embrionario, y a ese conjunto de genes se le denomina «genes embrionarios». Estos estudios analizan la expresión de ese grupo de genes, más concretamente, la presencia de proteínas codificadas por esos genes, y concluyen, al no detectar tales productos proteicos en los primeros estadios, que la activación del genoma del embrión no se produce hasta que se completan varios ciclos mitóticos. Los datos aparentemente dan a entender, a todo el que se acerque a consultarlos, que no existe expresión en los genes del embrión en sus primeros estadios, que el genoma, en el primer ciclo mitótico, está inactivo. Pues bien, tal y como he mostrado en otro lugar, y como ya se pude intuir con lo aquí puntualizado, esto es del todo incorrecto, y lo es por dos motivos: primero, porque los denominados «genes del embrión» establecidos por la comunidad científica no incluyen todos los genes del embrión y, segundo, porque la actividad del material genético también ha de recoger la replicación del ADN y, si la entendemos como expresión génica, debiera incluir la transcripción. ${ }^{8}$ Vemos, con este ejemplo, que hemos de prestar atención a la metodología y a letra pequeña de los experimentos científicos ya que, en ocasiones, el alcance de sus conclusiones no es lo que parece.

\section{SOBRE EL TIEMPO Y EL SISTEMA}

Ahora nos referiremos a un problema de tinte más filosófico que, en mi opinión, conviene tener presente cuando se reflexiona sobre la caracterización de los vivientes. Cuando un ser vivo es entendido como un sistema, se está comprendiendo, dicho sencillamente para los intereses de este subapartado, como un conjunto de relaciones entre elementos interconectados que forman una estructura estable. Este es el motivo por el que es habitual que en la bibliografía los sistemas vivos se ilustren a modo de formas geométricas cerradas. El cuadrado o círculo con el que suele ilustrarse al viviente como punto de partida de las reflexiones representa el modo de entender al ser vivo, modo que «paraliza» al viviente en una estructura estable. Este modo de entenderlo no contradice que

embryonic genome activation predicts development to the blastocyst stage», Nature Biotechnology, 28 (2010), pp. 1115-1121.

7 F. Güell op. cit.

8 Por otra parte, y sin querer entrar en más detalles, si la síntesis de proteínas se realiza en su mayoría desde los ARN mensajeros de origen materno y encontramos abundante ARN no codificante de origen gamético es por una estrategia metabólica del sistema: la existencia y uso del ARN mensajero para formar proteínas y la actividad funcional del ARN no codificante de origen espermático y ovular en el sistema devenido de la interacción gamética elimina la necesidad de una transcripción extensiva del genoma del embrión por la ARN polimerasa, la cual podría interferir con la rápida replicación del genoma por la ADN Polimerasa (D. S. Latchman, Gen control, New York: Garland Science, 2010, pp. 273-277). 
el sistema sea dinámico y se encuentre, por ejemplo, en constante relación con el medio. Se presupone entonces que el sistema de partida se encuentra en un tiempo 0 (St0), sistema que, aunque no se ilustre por motivos prácticos, ${ }^{9}$ conduce a un St1, St2, Stx. En estas aproximaciones sistemáticas al viviente, el tiempo es una variable externa del sistema que permite introducir el dinamismo.

Quiero llamar la atención a este respecto pues, en mi opinión, lo que caracteriza a los vivientes frente a otras realidades es que, justamente, el tiempo ha de entenderse como algo intrínseco ${ }^{10}$ y no como una variable del sistema que pueda extraerse. Cristalizar al viviente y mostrarlo como un sistema que pasa de St1 a St2 es, como trataré de mostrar a continuación, violentar la «cruda realidad» antes de cualquier reflexión que pretenda dar explicación de su estabilidad y de su cambio.

Encontramos aproximaciones que, a grandes rasgos, y si tomamos el viviente como un sistema en relación con su entorno, enfocan su estudio en la autorreproducción y/o el automantenimiento. Estas poseen un punto de partida, el viviente, como algo estable -el cuadrado dibujado-, una estructura que, con sus interacciones con el medio y a través de distintos procesos, ha de mantener su estabilidad. Pienso que si contemplamos atentamente a la realidad de la que partimos, es decir, al viviente, lo que lo caracteriza no es ser una realidad estructurada sino estar estructurándose. Por este motivo, afirmo que el tiempo es algo intrínseco al viviente. Si esto fuera así, habría que pensar si aquellas aproximaciones a las que hacía referencia, aun ofreciendo interesantes análisis, no están, a priori, presas por su modo de entender al viviente o, si se quiere, limitadas por el modelo desde el que se aproximan.

\section{SOBRE LA INDIVIDUALIDAD Y EL INDIVIDUO}

Otro de los problemas es el de la individualidad, es decir, a qué llamamos o a qué se debe llamar individuo. Aun en constante revisión, ${ }^{11}$ este asunto sigue, en mi opinión, empañando muchas de las reflexiones de la filosofía de la biología. Aunque se podría precisar con más detalle, en las reflexiones entorno a los seres vivos nos encontramos que, habitualmente, se dice individual de un gen, del genoma, de la célula, del órgano, del viviente, de la población y de la especie o de cualquier taxón.

9 Por ejemplo, el dinamismo del sistema con la interacción con el medio es normalmente ilustrada con flechas de ida y vuelta.

10 A este respecto, es muy sugerente el estudio $c f$. J. I. Murillo, «El tiempo y los métodos de la biología», Studia Poliana, 2 (2010), pp. 55-68.

11 Por ejemplo, $c f$. E. Clarke, «The problem of biological individuality», Biological Theory, 54 (2010), pp. 312-325. 
En mi opinión, que de todos se pueda decir «uno» ha conducido al olvido de analizar detenidamente la realidad antes de comenzar a reflexionar sobre ella. Siguiendo ahora a Zubiri, habría que distinguir la singularidad numeral de ser «uno» (efectivamente, igual de uno son los ejemplos antes citados), del modo de ser uno, de la índole de la unidad. ${ }^{12}$ Otros dirán que la individualidad se da de modo distinto en distintas realidades, pero ¿qué significa que «se da»?, ¿y cuál es esa distinción de modo? Repensar la unidad y, más concretamente, la relación entre el todo y las partes, puede ofrecer mucha luz a la hora de caracterizar los distintos tipos de realidades. De hecho, y tal y como he desarrollado en otro lugar, ${ }^{13}$ el estudio atento de la unidad y la multiplicidad muestra que el modo de ser individual de los seres vivos es un carácter no ya distintivo, sino definitorio.

Aunque es necesario recurrir a la dimensión taxonómica para conocer y situar completamente la realidad del viviente, en mi opinión, se ha producido una entificación de la noción de especie hasta llegar a considerarla, al igual que un organismo, una entidad individual real. ${ }^{14}$ Pienso que, además de repensar la noción de «individual», habría que explicar qué se entiende por «real». No menos importante será conocer los compromisos y exigencias que implica para el raciocinio afirmar que una especie es una entidad individual real como lo es un organismo. Pienso que, para que las cosas cuadren, cabe el peligro de que se tengan que estirar en demasía -hasta romperse-el significado de atributos tales como «parte», y vaciar algunos otros, como el de «individuo». Esto, además de eliminar el potencial explicativo de tales atributos para distinguir unidades tan dispares como piedras, organismos, máquinas, islas, instituciones y galaxias, obligaría - por ser, de hecho, las unidades de distinta índole- a discurrir sobre nuevas distinciones en el, por su ambigüedad, cómodo marco de partida. En mi opinión, un hecho que no debiera perderse de vista en las reflexiones que tratan de comprender y relacionar la dimensión orgánica y taxonómica es aquello que da razón de ser a cada especie: la generación que, indefectiblemente, solo acontece a nivel del organismo.

Algo parecido ocurre si se desciende en la escala y hablamos de la individualidad de un organismo, de un órgano, de una célula, de un genoma y de un gen. A este respecto, y como ya hemos indicado, las ciencias son, en gran parte, las responsables de ofrecernos información que, aun práctica y suficiente para el avance científico, crea en el imaginario del que lleva a cabo una reflexión

$12 C f$. X. Zubiri, Sobre la esencia, $2^{\circ}$ ed., Madrid: Alianza Ed., 2008, pp. 138 ss.

13 F. Güell, op. cit.

14 W. Hennig,Elementos de una sistemática filogenética. Buenos Aires: EUDEBA, 1968; M. Ghiselin, M. «A radical solution to the species problem», Systematic Zoology, 23 4(1974), pp. 536-544 y, recientemente, G. Caponi, «Linajes y sistemas: dos tipos de individuos biológicos», Scientiae Studia, Sâo Paulo, 102 (2012), pp. 243-268. 
metacientífica una realidad distinta a la «cruda realidad». Como ya he indicado, el problema de la individualidad es un problema derivado de la relación entre la unidad y la multiplicidad, problema al que dedicaremos el siguiente apartado, y con el que completaremos este análisis.

\section{SOBRE LA UNIDAD Y LA NOCIÓN DE FUNCIÓN}

El debate en torno a la función y a la explicación funcional en el viviente es uno de los temas más importantes de la filosofía de la biología. En el examen de las teorías sobre la noción de función ${ }^{15}$ se pueden destacar tres corrientes: la evolutiva, ${ }^{16}$ la sistémica ${ }^{17}$ y la organizacional. ${ }^{18}$ Lo que me interesa hacer notar ahora es que en esta concurrida discusión apenas se presta atención a la «unidad del viviente». Sintéticamente se puede afirmar que los evolutivos, simplemente, no la han convertido en un tema de análisis, y los sistémicos -eminentemente mecanicistas-, aunque suponen una cierta unidad, se desentienden de su caracterización al otorgar prioridad a las partes. La teoría organizacional intenta dar respuesta a algunas dificultades que hasta ahora no parece posible resolver en el marco de las teorías sistémicas y evolutivas, y aunque aluden a la unidad del organismo, no parecen tener suficientemente en cuenta-como tampoco lo hacen las teorías evolutivas y las sistémicas- un hecho que vamos aquí a de-

15 C. Allen, M. Bekoff y G.V. Lauder (eds.), Nature's Purposes: Analyses of Function and Design in Biology, Cambridge: MIT Press, 1997; D. J. Buller (ed.), Function, Selection and Design, Albany: State University of New York Press, 1999; A. R. Ariew, R. Cummins, M. Perlman (eds.), Functions: New Essays in the Philosophy of Psychology and Biology, Oxford: Oxford University Press, 2002; A. G. Wouters, «The functional perspective of organismic biology», en A. C. Reydon y L. Hemerick (eds.), Current Themes in Theoretical Biology, Netherlands: Springer, 2005, pp. 33-69 y F. J. Ayala y R. Arp (eds.), Contemporary Debates in Philosophy of Biology, Reino Unido: Wiley-Blackwell Malden, 2010.

16 L. Wright, «Functions», Philosophical review, 82 (1973), pp.139-168; R. Arp, «Evolution and two popular proposals for the definition of function», Journal for General Philosophy of Science, 38 (2007), pp. 19-30 y M. Pearlman, «Changing the Mission of Theories of Teleology: Do's and Don't's for Thinking About Function», en U. Krohs y P. Kroes (eds.), Functions in Biological and Artificial Worlds: Comparative Philosophical Perspectives, Cambridge, MA: Mit Press, 2009, pp. 17-36.

17 R. Cummins, «Functional analysis», Journal of Philosophy, 72 (1975), pp. 741-765; R. Cummins y M. Roth, «Traits have not evolved to function the way they do because of past advantage», en F. J. Ayala y R.Arp (eds.), Contemporary Debates in Philosophy of Biology, Reino Unido: Wiley-Blackwell Malden, 2010, pp. 72-88 y C. F. Craver, «Role Functions, mechanisms and hierarchy», Philosophy of science, 68 (2001), pp. 53-74.

18 W. D. Christensen y M. H. Bickhard, «The Process Dynamics of Normative Function», The Monist, 851 (2002), pp. 3-28 y C. Saborido, M. Mossio y A. Moreno, «Biological organization and Cross-Generation Functions», The british Journal for the philosophy if Science, 623 (2011), pp. 583-606. 
fender como central: en los seres vivos, se atribuye la función a una parte solo desde la unidad del viviente.

En mi opinión, una de las causas del olvido de la unidad del viviente y, en todo caso, de la falta de consideración de la prioridad de la unidad del viviente frente a su multiplicidad es, de nuevo, el modo inexacto de describir el hecho biológico sobre el que se discurre. Es común entender al viviente del modo como es explicado en los manuales de fisiología de las ciencias biológicas y biomédicas. En aquellas, el cuerpo se presenta organizado en sistemas: el nervioso, el muscular, el óseo, el reproductor, el digestivo, el respiratorio, etc, cada uno con sus aparatos y sus órganos, y todos ellos configurando un cuerpo. Se entiende, entonces, que el individuo es la suma de esos sistemas y órganos, cada cual con su función. Ciertamente, el modo más práctico que tienen las ciencias biomédicas de conocer el cuerpo y su funcionamiento es estudiarlo analizando sus partes y su relación. Pues bien, como decía, los análisis sobre el viviente han tomado la «realidad» sobre la que reflexionar de los datos y las descripciones que han ofrecido las ciencias. Esto se aprecia cuando en las reflexiones filosóficas sobre los seres vivos es habitual traer a colación, para apoyar o criticar teorías, los paradigmáticos ejemplos del corazón como órgano encargado de bombear sangre ${ }^{19}$ y el del pulmón como órgano al que se atribuye la función de respirar. ${ }^{20}$ En mi opinión, y siguiendo con el ejemplo citado, hay un hecho que suele pasar inadvertido: si se le adscribe al corazón la función de bombear sangre -y no, por ejemplo, la de hacer ruido- es porque sabemos que los nutrientes han de llegar a todos los rincones del cuerpo para alimentar a cada célula, y, por su parte, si se atribuye al pulmón la función de respirar es porque sabemos que las células que configuran la unidad del cuerpo necesitan oxígeno en su metabolismo. Creo, por este motivo, que sería interesante que las reflexiones sobre la función biológica recogieran la unidad del organismo como imprescindible para atribuir la función.

Algunas reflexiones se han percatado de la necesidad de aludir, en la atribución de una función, a un determinado proceso o sistema de referencia, y se han referido, más concretamente, al ciclo vital. ${ }^{21}$ La función, entonces, hace referencia a una parte, parte que contribuye con su función y coopera con la función del resto de partes al ciclo vital. Haré dos anotaciones a este respecto. En primer lugar, considero que podemos seguir varias vías de reflexión llegados

19 Por ejemplo, $c f$. M. Perlman, «Traits have evolved to function the way they do because of past advantage», en F. J. Ayala y R. Arp (eds.), Contemporary Debates in Philosophy of Biology, Reino Unido: Wiley-Blackwell Malden, 2010, pp. 53-71.

20 M. Artiga, «Re-Organizing Organizational Accounts of Function», Applied Ontology, 6 (2011), pp. 105-124.

21 G. Caponi, «Función, adaptación y diseño en biología», Signos filosóficos, 24 (2010), pp. 79 ss. 
a este punto: si atendemos al porqué algunos perfiles de una estructura orgánica fueron seleccionados, es decir, si lo que nos interesa del ciclo vital de referencia es fijarnos en su éxito adaptativo, tomaremos una vía en la que, por ejemplo, se dirá que la estructura está diseñada para el cumplimiento de una función que contribuyó a esa adaptación. ${ }^{22}$ Pero si atendemos al automantenimiento del ciclo vital, la reflexión sobre la función puede ir por otros derroteros, y lo mismo ocurre si lo que nos interesa es atender al desarrollo orgánico. En segundo lugar, considero importante anotar que estas propuestas siguen abordando la cuestión sin haber tematizado, primero, la relación entre la unidad y multiplicidad característica del viviente sobre el que se reflexiona.

Por otra parte, atribuir a un órgano una función es algo problemático. Por poner un ejemplo, afirmar que la función del pulmón es respiratoria, no es del todo correcto. La misma fisiología que trocea la realidad para comprenderla nos muestra que, por sus vasos sanguíneos, el pulmón forma parte del sistema cardiocirculatorio, que puede ser también considerado un órgano perteneciente al sistema inmunitario, y por sus nervios y ganglios, forma parte del sistema nervioso. ${ }^{23}$ En mi opinión, entender los órganos como partes separadas y separables de un todo no es fiel a la realidad. Intuyo que sería más adecuada una descripción de la multiplicidad que encontramos en el viviente si atendiéramos a los tejidos y a sus relaciones.

\section{EL VIVIENTE DESDE EL PARADIGMA CONSTITUCIONAL}

En mi opinión, lo más característico de la realidad de un viviente no es ni un tipo particular de interacción con el entorno, ni la autoproducción de sus redes moleculares, ni el automantenimiento de su estructura, ni su adaptación al medio. Efectivamente, sin todo esto no puede entenderse completamente lo que es un viviente, pero pienso que lo más carácterístico de los seres vivos es, inspirándome en el modo de atender a la realidades vivas de Xabier Zubiri en su teoría de la sustantividad, ${ }^{24}$ que son unidades constitucionales en interna determinación. ${ }^{25}$ Por motivos de espacio no puedo mostrar el «paradigma

22 ibid.p. 94.

23 A. Serani Merlo, El viviente humano. Estudios biofilosóficos y antropológicos, Pamplona: Eunsa, 2000, p. 38

24 Principalmente en $c f$. X. Zubiri, Sobre la esencia, $2^{\circ}$ ed., Madrid: Alianza Ed., 2008, pp. 95-371. Para una síntesis de carácter filosófico, $c f$. F. Güell, «Teoría zubiriana de la esencia (I): sobre lo esenciable y lo esenciado», Cuadernos Salmantinos de Filosofía, XXXVIII (2011), pp. 165-207 y F. Güell, «Teoría zubiriana de la esencia (II): sobre la esencia», Cuadernos Salmantinos de Filosofía, XXXIX (2012), pp. 309-368.

25 Para una exposición completa del planteamiento filosófico zubiriano aplicado a la caracterización del viviente, $c f$. F. Güell, El estatuto biológico y ontológico del embrión humano: el paradigma epigenético del siglo XXI desde la teoría de la esencia de Xavier Zubiri, Berna: 
constitucional» desde el que abordar la caracterización del viviente, pero este paradigma puede intuirse con facilidad.

La aproximación constitucional parte de dos intuiciones. Por un lado, uno de los caracteres distintivos del organismo frente a otras realidades es su desarrollo. Se suele acudir a «sistemas» ya adultos o a procariontes para discurrir sobre qué es lo característico de los sistemas vivos, pero, en mi opinión, esto deja al observador ciego para algo que es distintivo de los seres vivos: la linealidad y dinamismo de la diferenciación y proliferación celular es algo asombroso que no tiene parangón en toda la realidad. Quien compare y busque las semejanzas de lo que acontece en un ser vivo con lo que acontece en cualquier molécula, en una piedra, en una estalactita, en un archipliélago, en la tectónica de placas, en una llama, o en cualquier máquina, corre el riesgo de caer presa de un modelo mental preconcebido, y esto le privaría de contemplar sin interferencias -es decir, antes de cualquier búsqueda de semejanzas, reflexión e interés- lo absolutamente asombroso y único de la dinámica estructurante que encontramos en la unidad del viviente. Esta intuición ha de llevarnos a una caracterización esencial de la dinámica estructurante del viviente que incluya lo acontecido en los procariotas, y para ello, entiendo, ha de centrarse en el análisis de la unidad y la multiplicidad de todo ser vivo.

Un ejemplo me servirá para presentar la segunda intuición. Un ladrido ante ese desconocido que se acerca no es solo algo irreductible a las partes de este perro del modo como es irreductible a sus átomos la nueva polaridad de la molécula de agua (es decir, ni el ladrido ni la polaridad de la molécula se puede distribuir en operación perfectamente inversa a la adición de los elementos del perro y de la molécula de agua). Ese ladrido es un tipo de novedad que no encontramos en ninguna de sus partes, novedad que solo tiene razón de ser desde la unidad estructural en respuesta ante una situación que, de hecho, en nada afecta a las partes del perro, que, de un modo reduccionista, podríamos designar como «responsables» de la acción de ladrar. En síntesis, podríamos afirmar que es el grupo hidroxilo del fenol el que acidifica, pero carece de sentido afirmar que son las patas del perro las que huyen. Atender a las propiedades sistemáticas, es decir, a aquellas propiedades que emergen de la totalidad de un sistema (y no de una parte del sistema) es un método que, en mi opinión, también puede ofrecer mucha luz en la caracterización de las distintas unidades de la realidad. ${ }^{26}$

Peter Lang, 2013, (en prensa).

26 Inspirado en X. Zubiri, Sobre la esencia, $2^{\circ}$ ed., Madrid: Alianza Ed., 2008, pp. 147 ss. y los comentarios de I. Ellacuría, «La idea de estructura en la filosofía de X. Zubiri», Realitas 1 (1974), pp. 71-139, he profundizado en este asunto en $c f$. F. Güell, El estatuto biológico y ontológico del embrión humano: el paradigma epigenético del siglo XXI desde la teoría de la esencia de Xavier Zubiri, Berna: Peter Lang, 2013, (en prensa). 
El paradigma constitucional ofrece un amplio marco donde se hace una distinción, a mi juicio, fundamental. Por un lado, se distingue el orden constitucional del orden a la pervivencia. Desde aquel, se explica al viviente en cuanto realidad autoestructurante y sistematizadora; desde este, se estudia la estabilidad de la estructuración del viviente y se explica su peculiar independencia del medio y control específico sobre él. Este paradigma concreta la relación y necesidad de la interacción del viviente con su entorno para su estructuración, autoestructuración que da cabida a la autorreplicación y al automantenimiento, y ofrece una descripción precisa del desarrollo biológico más allá de la proliferación y diferenciación celular. Todo el planteamiento inspirado en la obra zubiriana no es sino fruto del análisis de la relación concreta $-\mathrm{y}$ única frente a las realidades inertes-entre la multiplicidad de notas y la unidad del viviente. Esta aproximación tematiza la distintiva individualidad del organismo vivo no sólo frente a sistemas inertes, sino frente a otros tipos de unidades de materia viva como, por ejemplo, la de un cultivo de células madre.

Quiero concluir esta exposición insistiendo en uno de los problemas fundamentales que, en mi opinión, pueden arrastrar las aproximaciones a la realidad del viviente: la prioridad del modelo frente a la realidad. Antes de estudiar modelos teóricos y acercamos con ellos a la realidad para ver cómo mejorarlos, hemos de observarla detenidamente. Nuestros sentidos ya nos ponen trabas suficientes como para complicarnos más con esquemas preconcebidos. Ciertamente, los modelos facilitan que el observador penetre en una dimensión del problema, pero, a su vez, no hemos de perder de vista que el observador queda limitado por el modelo; por eso, insisto, es necesario contemplar pausadamente la realidad y tener una actitud crítica con los datos, nociones y descripciones que ofrece la ciencia. No es que se tenga que evitar todo modelo o paradigma; de hecho, en este último apartado he anunciado el marco que, pienso, puede ofrecer luz sobre la caracterización del viviente. Lo que no hemos de olvidar es que nos estamos aproximando a la realidad desde un paradigma, y es que el problema grave no es dar prioridad al modelo, sino que éste suplante a la realidad.

Francisco GüEll Pelayo es miembro del Instituto Cultura y Sociedad, Universidad de Navarra (España).

Línea de investigación:

El estudio de la unidad del viviente y la relación entre la biología y la subjetividad desde la filosofía de Xavier Zubiri. 
Publicaciones recientes:

GÜELL, F. «La deriva interpretativa zubiriana en el análisis sustantivo del embrión», Diálogo Filosófico, 82 (2012), pp. 73-88.

GÜELL, F. «Teoría zubiriana de la esencia (II): sobre la esencia», Cuadernos Salmantinos de Filosofía, XXXIX (2012), pp. 309-368.

Dirección electrónica: fguell@unav.es 